\title{
Effects of crop species richness on pest-natural enemy systems based on an experimental model system using a microlandscape
}

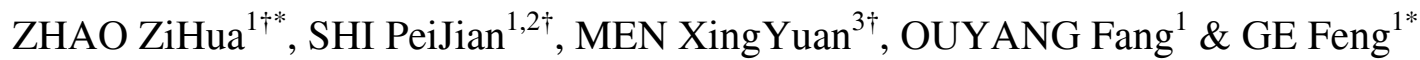 \\ ${ }^{1}$ State Key Laboratory of Integrated Management of Pest Insects and Rodents, Institute of Zoology, Chinese Academy of Sciences, Beijing \\ 100101, China; \\ ${ }^{2}$ Laboratory of Stock Assessment and Ecosystem Management, Yellow Sea Fisheries Research Institute, Chinese Academy of Fishery Sciences, \\ Qingdao 266071, China: \\ ${ }^{3}$ College of Plant Protection, Shandong Academy of Agricultural Sciences, Jinan 250100, China
}

Received January 7, 2013; accepted May 30, 2013; published online July 4, 2013

\begin{abstract}
The relationship between crop richness and predator-prey interactions as they relate to pest-natural enemy systems is a very important topic in ecology and greatly affects biological control services. The effects of crop arrangement on predator-prey interactions have received much attention as the basis for pest population management. To explore the internal mechanisms and factors driving the relationship between crop richness and pest population management, we designed an experimental model system of a microlandscape that included 50 plots and five treatments. Each treatment had 10 repetitions in each year from 2007 to 2010. The results showed that the biomass of pests and their natural enemies increased with increasing crop biomass and decreased with decreasing crop biomass; however, the effects of plant biomass on the pest and natural enemy biomass were not significant. The relationship between adjacent trophic levels was significant (such as pests and their natural enemies or crops and pests), whereas non-adjacent trophic levels (crops and natural enemies) did not significantly interact with each other. The ratio of natural enemy/pest biomass was the highest in the areas of four crop species that had the best biological control service. Having either low or high crop species richness did not enhance the pest population management service and lead to loss of biological control. Although the resource concentration hypothesis was not well supported by our results, high crop species richness could suppress the pest population, indicating that crop species richness could enhance biological control services. These results could be applied in habitat management aimed at biological control, provide the theoretical basis for agricultural landscape design, and also suggest new methods for integrated pest management.
\end{abstract}

biological control service, biomass, habitat management, microlandscape, trophic level

Citation: Zhao Z H, Shi P J, Men X Y, et al. Effects of crop species richness on pest-natural enemy systems based on an experimental model system using a microlandscape. Sci China Life Sci, 2013, 56: 758-766, doi: 10.1007/s11427-013-4511-3

Agro-ecosystems are composed of a variety of cultured crops grown mostly for human consumption, and simultaneously supply multiple ecosystem services. In these ecosystems, tri-trophic level interactions (crop, pest, and natural enemy) are an important component and have evolved close relationships. Indeed, the effect of species composi-

$\dagger$ Contributed equally to this work

*Corresponding author (email: gef@ioz.ac.cn; zihuazhao@126.com) tion and community structure on yields and ecosystem services is a very popular topic in ecology [1]. Some studies have reported that plant species richness directly affects species composition and the abundance of pests, which would influence the biological control services provided by natural enemies [2,3]. Indeed, a high level of plant diversity (e.g., intercropping, non-tillage, and weeds) could suppress pest populations and reduce yield losses caused by pest damage [4]. Root [5] proposed two hypotheses (the resource 
concentration hypothesis and the natural enemy hypothesis) to interpret these phenomena. The resource concentration hypothesis suggests that pest populations will increase during periods of high host density and decrease with low host density. In contrast, the natural enemy hypothesis states that high plant species richness can provide abundant resources and refuge for natural enemies (predators and parasitoids), greatly enhancing the activity of natural enemies and suppressing pest populations [6]. However, Andow found that high plant species richness did not always facilitate the biological control of pests [7], and only $52 \%-53 \%$ of pest species can be affected by plant species richness [2]. In fact, no consensus has been reached based on this type of research to date. Therefore, the effect of plant species richness on biodiversity and the biological control service of natural enemies in agro-ecosystems is currently an important research topic [8].

Agro-ecosystems have experienced major landscape changes in the last few decades caused by agricultural intensification, including the expansion of arable lands and landscape simplification, both of which drive loss of biological control services in agricultural landscapes [7,8]. In China, approximate $10 \%$ of crop yields were estimated to be destroyed by pests before the harvest of various crops, despite the use of a variety of crop protection measures including the widespread use of chemical pesticides. These processes have led to serious environmental problems. However, previous studies have found that the intercropping of two crops could improve biological control services; however, the effects of multiple crop species (three or more species) on pest damage and natural enemies have rarely been reported. Recently, experimental model systems (EMSs) of microlandscapes have been used to analyze the relationship between plant species richness and the diversity of insects on grasslands [3,9]. Accordingly, this EMS method provides a promising tool that can be used to study the effects of crop composition on pest damage and the biological control services provided by natural enemies of crop species.

Agricultural landscapes and the local management of arable lands can influence the abundance and composition of pest species present in an area. In the last few decades, frequent outbreaks of pests believed to have been caused by landscape simplification and agricultural intensification have brought large risks for agricultural production and have endangered the ability of farmers to secure adequate food supplies [10,11]. Therefore, ecological research has focused on creating ways to design healthy agricultural landscapes and to renew the stability of agro-ecosystems by achieving biological control of pest species [12]. Nonetheless, a large number of pest and natural enemy species exist in any specific crop ecosystem. For example, cereal aphids are parasitized by more than 17 parasitoid species [12]; in addition, more than 10 pest species exist in wheat fields. Similar situations exist in other crop ecosystems (e.g., cotton, rice, and corn), and this large number of species in a single ecosystem creates difficulties for community analysis. Fortunately, biomass analysis, a method that mainly considers material recycling and energy flow, provides an effective method which can be used to study predator-prey interactions related to agricultural plants, associated pest species and the natural enemy species of agricultural pests. Thus, we can place all species in one trophic level into a group and analyze the tri-trophic interactions (plant, pest, and natural enemy) $[13,14]$.

The Huang-Huai-Hai Plain in North China is one of China's most important grain producing regions. In the last few decades, population growth and changes in agricultural management and planting patterns have caused landscape simplification and a loss of biodiversity in the region's agro-ecosystems [15-18]. In particular, the rapid expansion of the monoculturing of crops has led to serious outbreaks of agricultural pests and the loss of biological control agents. Crop species richness facilitates biological control through the use of natural enemies of plant pest species in annual arable systems. However, agricultural intensification has led to high levels of landscape simplification and a reduction of habitat heterogeneity. In the present experiment, we studied the relationships between crop species richness and the biomass of pests and natural enemies based on a microlandscape EMS. Two hypotheses were tested: (i) based on the resource concentration hypothesis, high crop species richness suppresses pest populations, whereas decreased crop species richness will result in increases in pest species populations [19]; (ii) based on the natural enemy hypothesis, high crop species richness would supply abundant resources and refuge for natural enemies, which would indirectly improve the biological control service they provide and suppress pest populations [20]. The aim of this experiment was to achieve multiple ecological services and to supply a theoretical basis for potential pest management [21].

\section{Materials and methods}

\section{1 study region}

The study region is located in the county of Yishui, Linyi

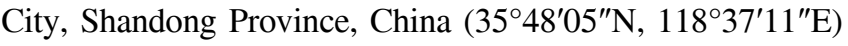
and has a temperate maritime monsoon climate with an elevation of 101.1-916.1 m. The region receives an average $2421 \mathrm{~h}$ of sunshine annually and has an annual average temperature of $14.1^{\circ} \mathrm{C}$. The value of effective accumulated temperatures above $10^{\circ} \mathrm{C}$ is $2390^{\circ} \mathrm{C}$ and the frost-free period is longer than $200 \mathrm{~d}$. The average annual precipitation is $849 \mathrm{~mm}$; the average annual evaporation capacity is $1773.5 \mathrm{~mm}$. In the center of this agricultural region, grain is produced from several important crops (e.g., wheat, cotton, and corn) which grow mainly on Podzol E soil. 


\subsection{Study site}

An experimental microlandscape (EMS) was implemented $[17,18]$. Twenty primary crop species commonly grown in North China were selected, including Gossypium spp., Zea mays L., Triticum aestivum L., Glycine max (L.) Merr., Solanum lycopersicum L., Brassica oleracea L., Setaria italica (L.) Beauv., Sorghum bicolor (L.) Moench, Lolium perenne L., Vigna angularis (Willd.) Ohwi et Ohashi, Arachis hypogaea L., Vigna radiata (L.) R. Wilczek, Medicago sativa L., Solanum melongena L., Apium graveolens L., Trifolium repens L., Helianthus annuus L., Phaseolus vulgaris L., Brassica napus L., and Sesamum indicum L. Five plant richness levels $(1,2,4,8$, and 16) were designed, and we randomly selected $1,2,4,8$, and 16 species to achieve the five crop species richness levels. Every treatment was repeated 10 times. Fifty $9 \mathrm{~m} \times 9 \mathrm{~m}$ plots were used which were located $1 \mathrm{~m}$ apart; the entire experimental site covered $70 \mathrm{~m} \times 150 \mathrm{~m}$ (Figure 1). For a given plot, the crops were distributed in a matrix of 22 rows and 22 columns.

The crop density and amount of fertilizer use was the same in each plot so that the study sites were homogeneous. Herbicide was applied to the unplanted area between the plots to suppress weed growth. In this experiment, we only considered the effect of crop species richness on pests and natural enemies. No pesticides, herbicides, chemical fertilizers, or other agrichemicals were applied to any of the crops in any of the plots. Weeds were removed by hand. These management practices were expected to largely decrease the external disturbance to the insect community. The distance between the experimental site and surrounding landscape was $5 \mathrm{~m}$. In addition, the corn fields in the landscape surrounding the study area provided homogeneous buffer habitat, which was expected to eliminate stochastic disturbance (Figure 1). Crop species richness (N) and crop arrangements in each plot remained the same during the four-year study (2007-2010).

\subsection{Study methods}

\subsubsection{Insect sampling}

A cross-sectional sampling method was used in these experiments, which is similar to a parallel sampling method. We only sampled one row with 22 plants in the center line in each plot (Figure 1). This uniform collection method was designed to minimize edge effects caused by the surrounding habitat. All insect species and their abundance (pests and natural enemies) on the 22 plants (center line) were recorded. We collected insect samples five times in each year, or once a month in April, May, June, July, and August, during the crop growing season. The species composition and abundance of pest species and their natural enemies were carefully recorded. To reduce disturbance to the plants, insect populations on the abaxial and adaxial leaf surfaces were studied using a handheld mirror and by visual observation, respectively. Small insects were surveyed using an insect magnifier. These processes were expected to greatly decrease the human disturbance. Every plant was carefully surveyed for $10 \mathrm{~min}$. The instars, state, and injury characteristics of pests were recorded at the same time; the investigations in each plot required an average of $220 \mathrm{~min}$. The insect density was transformed to individuals/22 plants based on the cross-sectional sampling method (Figure 1).

\subsubsection{Biomass determination}

The total dry organic matter of plants and insects (pests and natural enemies) was determined. Below- and above-ground plant parts were transported to the lab and their biomasses were determined after $72 \mathrm{~h}$ of drying at $60^{\circ} \mathrm{C}$. Large plants (e.g., corn) were cut into several sections, and we calculated the biomass by summing these several sections. Each test involved three repetitions for every crop species. The same

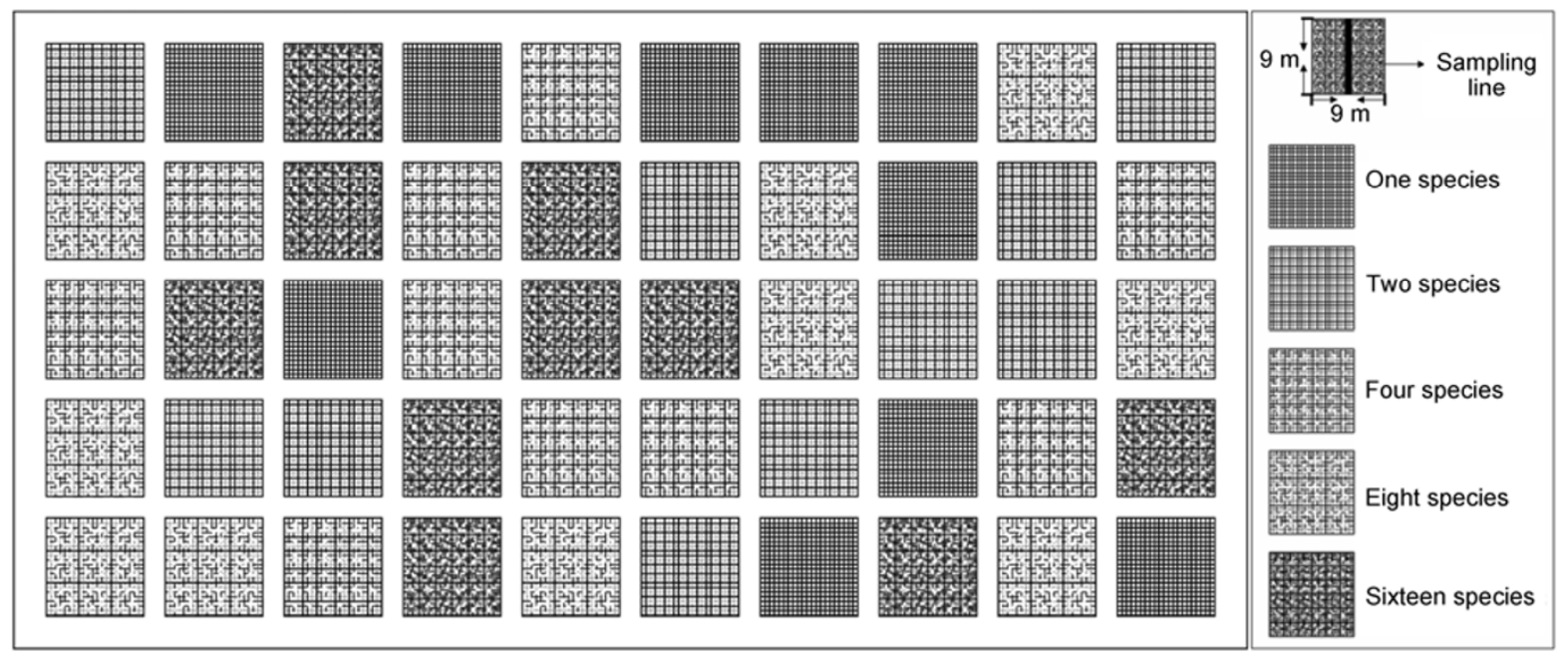

Figure 1 Crop arrangement and composition in an experimental model system (EMS) of a microlandscape. 
methods were used to determine the biomass of pests and natural enemies $\left(60^{\circ} \mathrm{C}\right.$ drying for $\left.72 \mathrm{~h}\right)$. Small insect biomass (aphids, aleyrodid, and thrips) was determined as $\mathrm{g} / 100$ individuals to calculate the mean value (g/individual); the biomass of other arthropods (spiders, carabid, and plant hoppers) was determined individually. Five repetitions were conducted for each insect species.

\subsubsection{Transformation of insect population biomass}

All insect species were divided into two groups (pests and natural enemies); neutral insects (honeybees, flies, and mosquitoes) were excluded from the analysis. The biomass of individual insect species was first determined; then the biomass of each pest and natural enemy species was calculated based on its population density. The crop biomass was obtained by the same method.

\subsection{Statistical analysis}

\subsubsection{Biomass of tri-trophic levels (crop-pest-natural en- emy)}

The tri-trophic level interactions were determined by a correlation analysis, and the biomass of each of the three trophic levels (crop, pest, natural enemy or tri-trophic if considered as a group) was calculated. We did not consider interspecies relationships or specific species and only tested the correlation relationship at the tri-trophic level. The effects of crop species richness on biological control services were measured. Neutral insects that supply pollination and/or decomposition functions in agro-ecosystems were excluded from the analysis.

\subsubsection{Biological control service}

The ratio of biomass (natural enemy/pest) was established as an index of the biological control service [22], by investigating the insect populations on 22 different plants on the center line in the different experimental plots. Therefore, we

calculated the ratio of natural enemy biomass to pest biomass to represent the biological control service provided by each natural enemy species.

\subsubsection{Generalized additive model}

The generalized additive model (GAM) is a non-parametric method of local regression that explores the relationships between variables [23]. In this experiment, two generalized additive models were constructed. The first model aimed to analyze the effects of sampling time, pest biomass, and crop biomass on the natural enemy biomass (eq. (1)):

$$
y=\alpha+s_{1}\left(x_{1}\right)+s_{2}\left(x_{2}\right)+s_{3}\left(x_{3}\right)+\varepsilon .
$$

This model was composed by smoothing functions, which included three spline functions: $s_{1}, s_{2}$, and $s_{3}$. $x_{1}$ represents sampling time, $x_{2}$ represents pest biomass, $x_{3}$ represents crop biomass, $\varepsilon$ represents the error term, and $y$ represents natural enemy biomass. Parameter $\alpha$ was also added into the model. This GAM has been widely used in ecology, which was applied to analyze the non-linear relationship.

The second model could be constructed by the same method, which analyzed effects of sampling time, natural enemy biomass, and crop biomass on pest biomass (eq. (2)):

$$
x_{2}=\alpha+s_{1}\left(x_{1}\right)+s_{4}(y)+s_{3}\left(x_{3}\right)+\varepsilon .
$$

These two generalized additive models were performed using R 2.11 (R Development Core Team, 2010) with package mgcv.

\subsubsection{Linear regression model}

The linear regression model was used to analyze the relationship of tri-trophic levels (crop, pest, and natural enemy). We first examined the relationship between pest biomass and natural enemy biomass. Then the other relationships (crop biomass and natural enemy biomass or crop biomass and pest biomass) were analyzed in a similar way. For checking the biological control services supplied by crop species richness, the analysis of variance was used to test whether the ratios of biomass (natural enemy/pest) at five crop species richness (i.e., 1, 2, 4, 8 and 16) were equal. The linear regression model was performed using R 2.11 (R Development Core Team, 2010).

\section{Results}

\subsection{Effects of crop species richness on pest and natural enemy biomass}

Crop species richness had major effects on the biomass of pests and natural enemies (Figure 2), with the pest biomass increasing with increasing crop species richness. However, the differences were not significant (Figure $2 \mathrm{~A}, F_{1.593}=1.464$, $P=0.227$ ). In addition, the natural enemy biomass also increased with increasing crop species richness, although the differences were not significant (Figure $2 \mathrm{~B}, F_{1.593}=0.682$, $P=0.409$ ). The mid-range value of the pest and natural enemy biomass peaked when the crop species richness was at a maximum $(N=16)$; the mid-range value of biomass was $0.12 \mathrm{~g} / 22$ plants and $0.04 \mathrm{~g} / 22$ plants, respectively. When the crop species richness was at a minimum $(N=1)$, the mid-range value of pest and natural enemy biomass was also low (pest, $0.04 \mathrm{~g} / 22$ plants; natural enemy, $0.03 \mathrm{~g} / 22$ plants).

\subsection{Relationship at the tri-trophic level (crop-pest- natural enemy)}

The relationship at the tri-trophic level was analyzed by generalized additive models. The effects of sampling time, pest biomass, and crop biomass on the natural enemy biomass were also analyzed (Figure 3 ). The sampling time had 

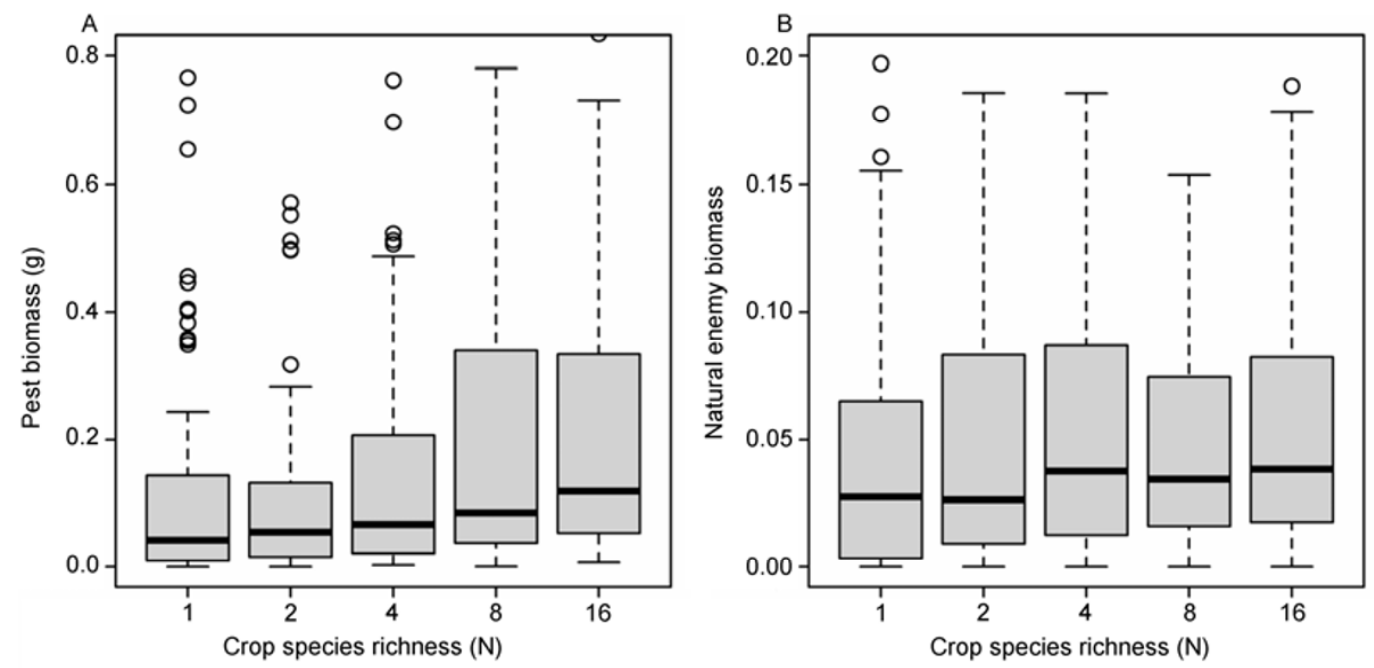

Figure 2 Relationship between crop richness and pest and natural enemy biomass.

significant effects on the biomass of natural enemies (Figure $\left.3 \mathrm{~A}, F_{1.000}=4.007, P=0.046\right)$. Although the crop biomass also had no significant effects on the natural enemy biomass (Figure 3E, $F_{1.044}=0.574, P=0.462$ ), the pest biomass did have significant effects (Figure $3 C, F_{8.846}=15.130, P<0.001$ ).

The sampling time had no significant effects on the pest biomass (Figure 3B, $F_{2.092}=1.908, P=0.136$ ), and the crop biomass also did (Figure 3F, $F_{1.893}=2.031, P=0.123$ ). In contrast, the natural enemy biomass did have significant effects on the pest biomass (Figure 3D, $F_{6.505}=9.478$, $P<0.001)$

\subsection{Effects of crop species richness on pest damage and biological control service}

The ratio of biomass (natural enemy/pest) was used to analyze the relationship between the biological control service and crop species richness. The results showed that the ratio of biomass (biological control service) first increased and then decreased with increasing crop species richness; the differences were significant (Figure 4A, $F_{4.593}=5.163$, $P=0.0234)$. The biological control service peaked when the crop species richness was 4 , with the median and mean of the natural enemy/pest ratio at the maximum (Figure 4A). In contrast, the median and mean of the natural enemy/pest ratio were both at a minimum when the crop species richness was 8 (Figure 4A).

The relationship between the pest and natural enemy biomass was positive and significant: the natural enemy biomass increased with increasing pest biomass (Figure 4B, $\left.F_{1.593}=32.79, r=0.2289, P<0.01\right)$. The relationship between the pest and crop biomass was also positive and significant: the pest biomass increased with increasing crop biomass (Figure 4D, $F_{1.593}=10.82, r=0.1338, P=0.0011$ ). However, no significant relationship existed between the crop and natural enemy biomasses (Figure $4 C, F_{1.593}=0.62, r=0.0323$, $P=0.4326)$.

\section{Discussion}

\subsection{Relationship between crop species richness and biomass of pests and natural enemies}

In this experiment, we designed five crop species richness levels to analyze the effects of the crop species richness on the biomass of pests and natural enemies based on EMS at the microlandscape level. The biomass of pests and natural enemies increased with increasing crop species richness. Therefore, the resource concentration hypothesis was not well supported by our results. This may occur because agricultural pests are polyphagous. Accordingly, the plot with the highest crop species richness supplied the most abundant food resources for pests [24,25]. For example, the cotton bollworm (Helicoverpa armigera Hübner, Lepidoptera: Noctuidae), which can feed on several hosts, including wheat, corn, cotton, and vegetables, has a high level of biomass in plots with high crop species richness [26,27]. In addition, multiple crop species also supply an abundance of prey and food resources for natural enemies. Although the biomass of pests and natural enemies increased with increasing crop species richness, the differences were not significant. This biomass method could simplify community analyses of pests and natural enemies in agro-ecosystems, and the biomass method could be used to study energy flow of plants-pests-natural enemies based on multiple crop systems $[14,28]$.

The diversity-yield relationship is an important aspect in biodiversity and ecological function and has received much attention [29]. Some studies report that high plant diversity can result in high yields [30-32]. However, Ge and Ding [7] found no relationship between species diversity and yield. In our experiments, we found that the adjacent trophic levels (pests and natural enemies and crop and pests) had significant linear correlations. The pest biomass increased with increasing crop biomass; similarly, the natural enemy bio- 

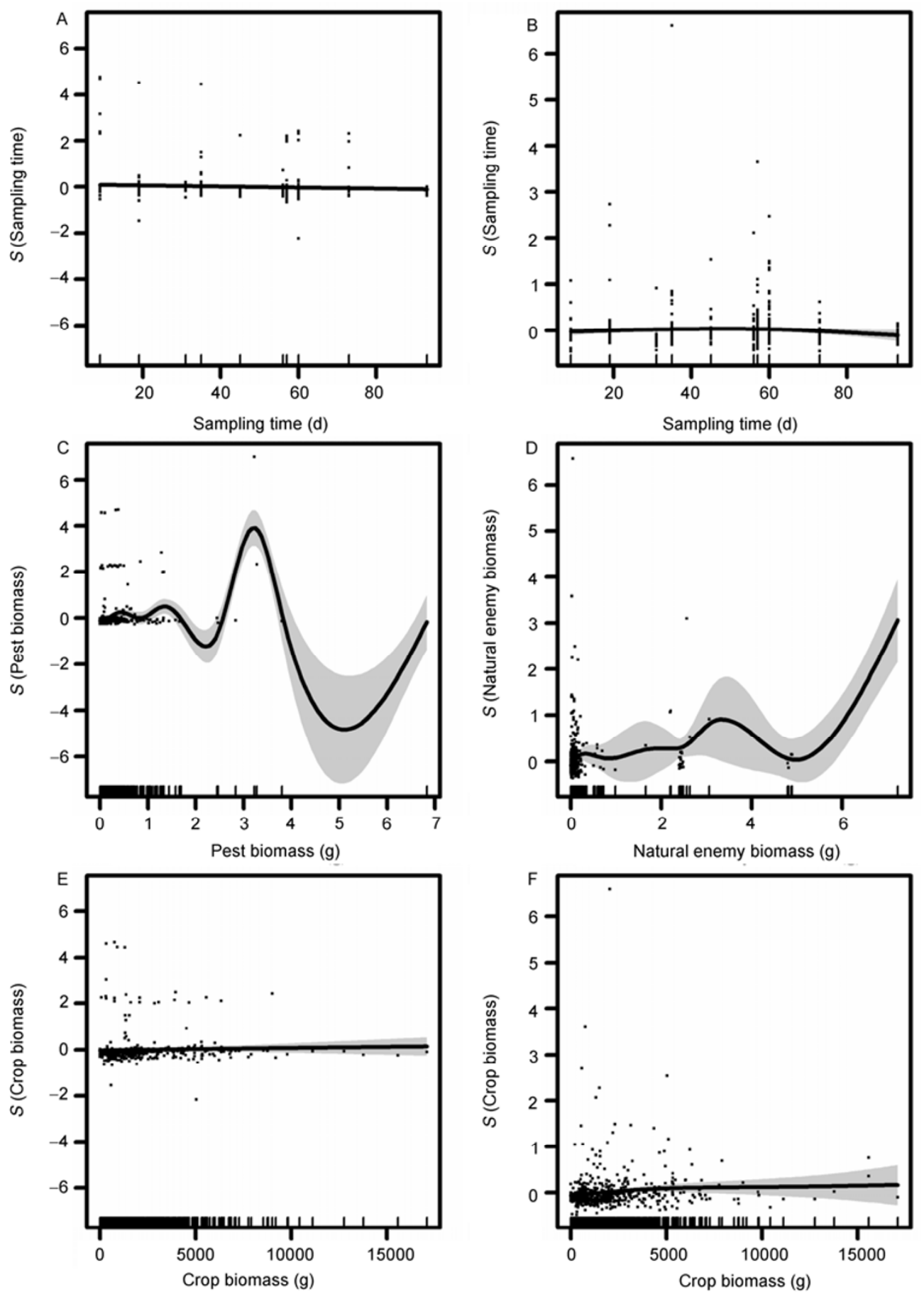

Figure 3 Relationships of sampling time and biomass in a generalized additive model (GAM). A, C, and E indicate the effects of sampling time, pest biomass, and crop biomass on natural enemies; B, D, and F indicate the effects of sampling time, natural enemy biomass, and crop biomass on pests.

mass increased with increasing pest biomass. Conversely, non-adjacent trophic levels (crop and natural enemies) showed no significant linear correlation. These results indicated that energy flow in agro-ecosystems might affect adjacent trophic levels; for non-adjacent trophic levels, energy flow and material recycling would show no significant effects.

\subsection{Effects of crop species richness on biological con- trol services in an agro-ecosystem}

Biodiversity in an agro-ecosystem has large effects on integrated pest management [6]. However, previous studies mainly focused on the effects of the intercropping of two crops on biological control services; indeed, related studies are rare for multiple crops (three or more species). In our 

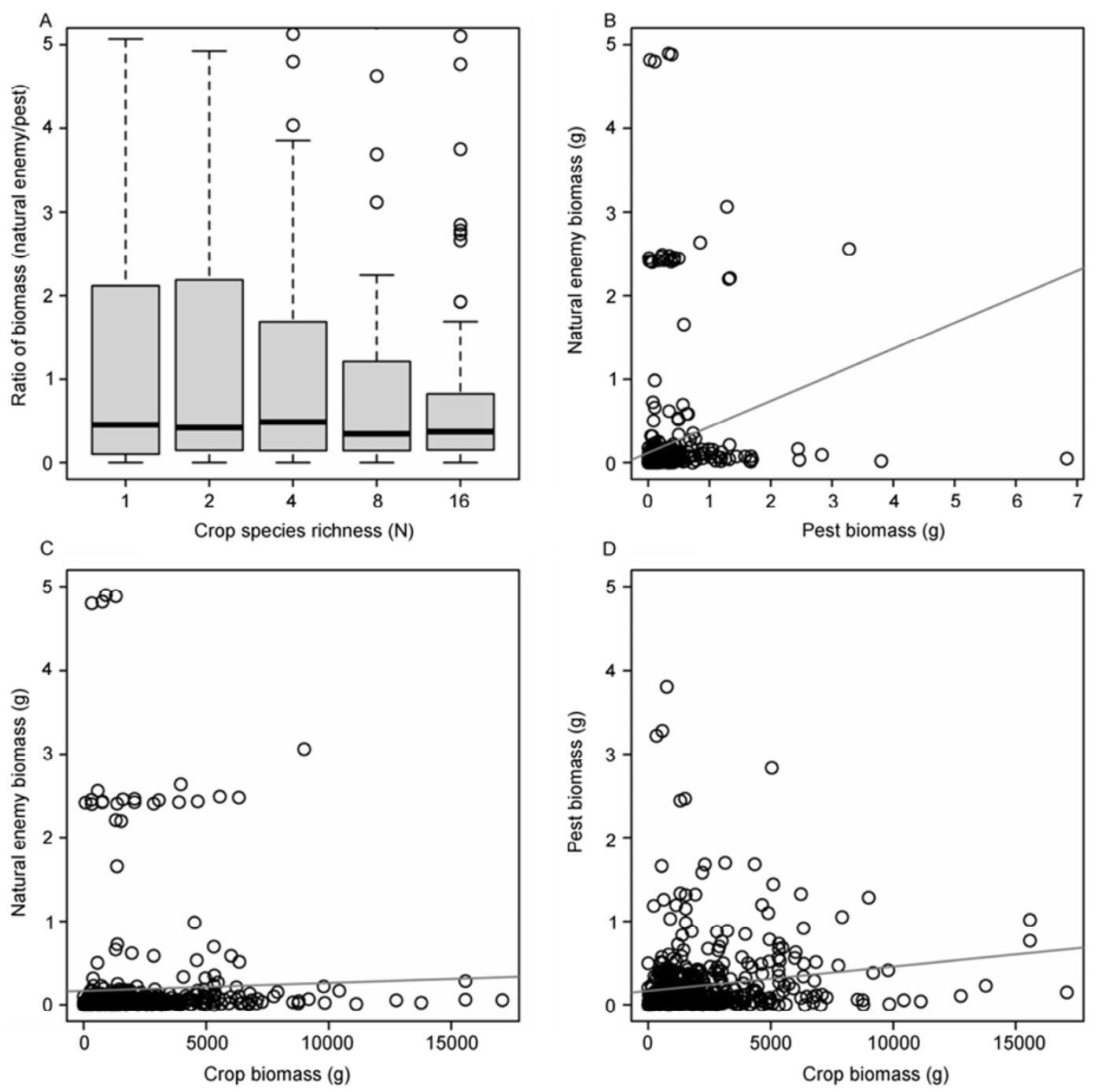

Figure 4 Tri-trophic level interactions of crop, pest, and natural enemy.

experiment, five crop species richness levels were designed to analyze the effects of the level of crop species richness on pests and natural enemies based on EMS at the microlandscape level. The biological control services (the ratio of biomass) were significantly affected by the crop species richness, as based on biomass methods, decreasing with increasing crop species richness. In addition, the biological control services peaked when the crop species richness was four. Two possible mechanisms could be invoked to interpret these findings: (i) high crop species richness could disturb the host-searching behaviors of pests, leading to the inadequate identification of a plant host $[33,34]$, or (ii) multiple crop species could supply alternative prey and refuge, enhancing the activity of natural enemies and improving the biological control service [35-37].

The relationships between crop arrangement and biological control services are among the most important issues in agro-ecosystems [38,39], and the methods used to manipulate habitat composition and agricultural management in mosaic landscapes to achieve biological control services are important aspects of ecological research. Such landscape designs should consider the dynamics of pests and natural enemies at different spatial and temporal scales. Polyphagous pests complicate these processes more than oligophagous pests. The biological control services were optimal when the crop species richness was 4 , showing that the biological control service could be improved through habitat manipulation and landscape design. Microlandscape EMS based on a small spatial scale provided a valuable tool which can be used to study the effects of crop arrangement and composition on biological control services. The plot in our experiments was $9 \mathrm{~m} \times 9 \mathrm{~m}$; however, other researchers have conducted experiments on a larger scale $(10 \mathrm{~m} \times 10 \mathrm{~m}$ and $30 \mathrm{~m} \times 30 \mathrm{~m})[40,41]$ or using smaller plots $(4.7 \mathrm{~m} \times 4.7 \mathrm{~m}$ and $2.4 \mathrm{~m} \times 2.4 \mathrm{~m}$ ) $[15,42]$. Future research should analyze the tri-trophic level interactions on a large spatial scale, which could produce reliable results $[20,43,44]$. All of these results could be applied in habitat manipulation aimed at 
pest biological control, provide a theoretical basic for agricultural landscape design, and also supply new methods for integrated pest management $[44,45]$.

Our finding on the effect of crop species richness on biomass of pest and natural enemy species can be applied in integrated pest management strategies that aim to incorporate crop composition and arrangement into habitat management as they suggest that successful biological control would mainly be effective through the use of well-planned landscape design and the creation of habitat diversity. Combining agricultural landscape design with biological control services may effectively address the ecological function of natural enemies when integrated pest management strategies are used regionally and may provide multiple ecosystem services $[46,47]$. Far less attention has been paid to additional ecosystem services that agricultural landscapes could provide as managed landscapes. Our results not only address the biological control of insect pests but also address other ecological services received through landscape design and habitat manipulation [48].

We are grateful to Prof. Hui Cang (Department of Botany and Zoology, Stellenbosch University) and Prof. He DaHan (Agricultural School, Ningxia University) for statistical advice on the first draft of this manuscript. We also thank Shandong Agricultural University (Gao YuanYang, Zhang Bo, Zhang XiaoPeng, Liu Ting, Liu Xin, Lou YanXia, Xu BingJie, and Ming ZhaoYue), Qingdao Agricultural University (Mao JingJing, Zhang GongTian, Ding YiWen, Ding Liang, Qu PengFei, and Xue QingQuan), and Hebei Agricultural University (Lv Fei, Cai XiaoYu, Hu YingXin, Ma Xin) for field assistance and insect collection. We also thank the farmers who allowed us to use their fields for our collections and investigations. This work was partly supported by the National Natural Science Foundation of China (31030012), National Key Technology Research \& Development Program (2012BAD19B05), and Special Fund for Agro-scientific Research in the Public Interest (201103012).

1 Ge F. The Theory and Method of Insect Ecology. Beijing: Higher Education Press, 2008

2 Andow D A. Vegetational diversity and arthropod population response. Annu Rev Entomol, 1991, 36: 561-586

3 Scherber C, Mwangi P N, Temperton V M, et al. Effects of plant diversity on invertebrate herbivory in experimental grassland. Oecologia, 2006, 147: 489-500

4 Men X Y, Ge F, Yardim E N, et al. Evaluation of winter wheat as a potential relay crop for enhancing biological control of cotton aphids in seedling cotton. Biocontrol, 2004, 49: 701-714

5 Root R B. Organization of a plant-arthropod association in simple and diverse habitats-fauna of Collards (Brassica-Oleracea). Ecol Monogr, 1973, 43: 95-120

6 Wenninger E J, Inouye R S. Insect community response to plant diversity and productivity in a sagebrush-steppe ecosystem. J Arid Environ, 2008, 72: 24-33

7 Ge F, Ding Y Q. Functional features of preserving natural enemies to control insect pests in intercropped cotton field ecosystems. Chinese J Appl Ecol, 1997, 8: 295-298

8 Cardinale B J, Srivastava D S, Duffy J E, et al. Effects of biodiversity on the functioning of trophic groups and ecosystems. Nature, 2006, 443: 989-992

9 Haddad N M, Tilman D, Haarstad J, et al. Contrasting effects of plant richness and composition on insect communities: A field experiment. Am Nat, 2001, 158: 17-35

10 Landis D A, Wratten S D, Gurr G M. Habitat management to con- serve natural enemies of arthropod pests in agriculture. Annu Rev Entomol, 2000, 45: 175-201

11 Menalled F D, Costamagna A C, Marino P C, et al. Temporal variation in the response of parasitoids to agricultural landscape structure. Agr Ecosyst Environ, 2003, 96: 29-35

12 Zhao Z H, Wang Y, He D H, et al. Effects of landscape structure and key landscape factors on aphids-parasitoids-hyper parasitoids in wheat fields. Acta Ecol Sin, 2012, 32: 472-482

13 Girma H, Rao M R, Day R, et al. Abundance of insect pests and their effects on biomass yields of single vs. multi-species planted fallows. Agroforestry Syst, 2006, 68: 93-102

14 Zhao Z H, He D H, Hui C. From the inverse density-area relationship to the minimum patch size of a host-parasitoid system. Ecol Res, 2012, 27: 303-309

15 Parker M, Nally R M. Habitat loss and the habitat fragmentation threshold: an experimental evaluation of impacts on richness and total abundances using grassland invertebrates. Biol Conserv, 2002, 105: 217-229

16 Trichard A, Alignier A, Biju-Duval L, et al. The relative effects of local management and landscape context on weed seed predation and carabid functional groups. Basic Appl Ecol, 2013, 14: 235-245

17 Huang Y, Martin L M, Isbell F I, et al. Is community persistence related to diversity? A test with prairie species in a long-term experiment. Basic Appl Ecol, 2013, 14: 199-207

18 With K A, Pavuk D M. Habitat area trumps fragmentation effects on arthropods in an experimental landscape system. Landscape Ecol, 2011, 26: 1035-1048

19 Hamback P A, Englund G. Patch area, population density and the scaling of migration rates: the resource concentration hypothesis revisited. Ecol Lett, 2005, 8: 1057-1065

20 Tscharntke T, Bommarco R, Clough Y, et al. Conservation biological control and enemy diversity on a landscape scale. Biol Control, 2008, 45: $238-253$

21 Werling B P, Gratton C. Influence of field margins and landscape context on ground beetle diversity in Wisconsin (USA) potato fields. Agr Ecosyst Environ, 2008, 128: 104-108

22 Ge F, Ding Y Q. The population energy dynamics of predacious natural enemies and their pest control activity in different cotton agroecosystems. Acta Entomol Sin, 1996, 39: 266-273

23 Dai J J, Sun L Q, Yang Z H. A general additive-multiplicative rates model for recurrent event data. Sci China Math, 2009, 52: 2257-2265

24 Frank T, Kehrli P, Germann C. Density and nutritional condition of carabid beetles in wildflower areas of different age. Agr Ecosyst Environ, 2007, 120: 377-383

25 Gagic V, Tscharntke T, Dormann C F, et al. Food web structure and biocontrol in a four-trophic level system across a landscape complexity gradient. P Roy Soc B-Biol Sci, 2011, 278: 2946-2953

26 Jonsson M, Buckley H L, Case B S, et al. Agricultural intensification drives landscape-context effects on host-parasitoid interactions in agroecosystems. J Appl Ecol, 2012, 49: 706-714

27 Lundy M G, Buckley D J, Boston E S M, et al. Behavioural context of multi-scale species distribution models assessed by radio-tracking. Basic Appl Ecol, 2012, 13: 88-195

28 Matsumoto T, Itioka T, Nishida T. Cascading effects of a specialist parasitoid on plant biomass in a Citrus agroecosystem. Ecol Res, 2003, 18: 651-659

29 Stein C, Auge H, Fischer M, et al. Dispersal and seed limitation affect diversity and productivity of montane grasslands. Oikos, 2008, 117: 1469-1478

30 Tilman D, Reich P B, Knops J, et al. Diversity and productivity in a long-term grassland experiment. Science, 2001, 294: 843-845

31 Singh S P, Sah P, Tyagi V, et al. Species diversity contributes to productivity-evidence from natural grassland communities of the Himalaya. Curr Sci India, 2005, 89: 548-552

32 Fornara D A, Tilman D. Ecological mechanisms associated with the positive diversity-productivity relationship in an $\mathrm{N}$-limited grassland. Ecology, 2009, 90: 408-418

33 Werling B P, Gratton C. Local and broadscale landscape structure differentially impact predation of two potato pests. Ecol Appl, 2010, 
20: 1114-1125

34 Schmidt-Entling M H, Dobeli J. Sown wildflower areas to enhance spiders in arable fields. Agr Ecosyst Environ, 2009, 133: 19-22

35 Pluess T, Opatovsky I, Gavish-Regev E, et al. Non-crop habitats in the landscape enhance spider diversity in wheat fields of a desert agroecosystem. Agr Ecosyst Environ, 2010, 137: 68-74

36 D'Alberto C F, Hoffmann A A, Thomson L J. Limited benefits of non-crop vegetation on spiders in Australian vineyards: regional or crop differences? Biocontrol, 2012, 57: 541-552

37 Hui C, Boonzaaier C, Boyero L. Estimating changes in species abundance from occupancy and aggregation. Basic Appl Ecol, 2012, 13: $169-117$

38 Messelink G J, Bloemhard C M J, Sabelis M W, et al. Biological control of aphids in the presence of thrips and their enemies. Biocontrol, 2013, 58: 45-55

39 Schmidt M H, Thies C, Nentwig W, et al. Contrasting responses of arable spiders to the landscape matrix at different spatial scales. J Biogeogr, 2008, 35: 157-166

40 Zhao Z H, Wang Y, He D H, et al. Effects of habit loss and fragmentation on species loss and colonization of insect communities in experimental alfalfa landscapes. Biodiversity Sci, 2011, 19: 453-462

41 Zaviezo T, Grez A A, Estades C F, et al. Effects of habitat loss, habitat fragmentation, and isolation on the density, species richness, and distribution of ladybeetles in manipulated alfalfa landscapes. Ecol Entomol, 2006, 31: 646-656

42 Grez A, Zaviezo T, Tischendorf L, et al. A transient, positive effect of habitat fragmentation on insect population densities. Oecologia, 2004, 141: 444-451

43 Zhao Z H, Ouyang F, He D H. Edge effects and spillover effects of natural enemies on different habitat interfaces of agricultural landscape. SCIENTIA SINICA Vitae, 2012, 42: 825-840

44 Zhao Z H, Guan X Q, He D H. Community composition of parasitoids and hyperparasitoids of wheat aphids in different agricultural landscapes. Chinese J Appl Entomol, 2012, 49: 220-229

45 Tscharntke T, Tylianakis J M, Rand T A, et al. Landscape moderation of biodiversity patterns and processes - eight hypotheses. Biol Rev, 2012, 87: 661-685

46 Cobbold S M, MacMahon J A. Guild mobility affects spider diversity: links between foraging behavior and sensitivity to adjacent vegetation structure. Basic Appl Ecol, 2012, 13: 597-605

47 Katsanis A, Babendreier D, Nentwig W, et al. Intraguild predation between the invasive ladybird Harmonia axyridis and non-target European coccinellid species. Biocontrol, 2013, 58: 73-83

48 Géneau C E, Wäckers F L, Luka H, et al. Selective flowers to enhance biological control of cabbage pests by parasitoids. Basic Appl Ecol, 2012, 13: 85-93

Open Access This article is distributed under the terms of the Creative Commons Attribution License which permits any use, distribution, and reproduction in any medium, provided the original author(s) and source are credited. 